\title{
Interannual changes of the ocean wave variability in the North Atlantic and in the North Sea
}

\author{
E. Bauer* \\ Potsdam Institute for Climate Impact Research, PO Box 601203, 14412 Potsdam, Germany
}

\begin{abstract}
A high-resolution ocean wave hindcast for 1981 to 1993 with the WAM wave model is used to study the mean sea state and its dominant modes of variability in the North Atlantic and in the North Sea. The wind and wave data share high correlation coefficients with the North Atlantic Oscillation (NAO) index of the winter season and rather low correlation coefficients with the monthly NAO index. The low correlations are induced by the different modes of variability. The NAO index varies at semiannual and shorter periods and the wind and wave data vary with the seasonal cycle. In addition, considerably unsteady variability is apparent at synoptic scales. The dominant modes of that variability, retrieved by a wavelet analysis, are similar for wind and wave data of the same year but may change considerably from year to year. From 1987 to 1989, when the NAO index increases, the dominant period of variability also increases. The same trend is inferred from wind and wave measurements at Ocean Weather Station M. In contrast, the dominant periods inferred from data of the southern North Sea show a reverse trend. This indicates that the wave variability in the North Sea is reduced when the westerlies are more zonal, and is intensified when the westerlies are less zonal through more meridional contributions initiated by the Northeast Atlantic wind and wave variability.
\end{abstract}

KEY WORDS: NAO index - Wind fields · Significant wave height - Wavelet power spectrum . Synoptic-scale variability

Resale or republication not permitted without written consent of the publisher

\section{INTRODUCTION}

Surface wind fields and wind-driven ocean waves exhibit large variability on a wide range of time scales. The variability we observe is composed of fluctuations on the weather scale and the seasonal scale, and of fluctuations on interannual to decadal scales associated with large-scale climate variations. The 1960s to 1990s time series of significant wave height $\left(H_{\mathrm{s}}\right)$ from the Northeast Atlantic show a significant upward trend (Bacon \& Carter 1991, Bouws et al. 1996). Bacon \& Carter (1993) indicated that the upward trend of annual mean $H_{\mathrm{s}}$ is connected to the increase of the large-scale gradient of sea level pressure between the Azores High and the Iceland Low represented by the North Atlantic Oscillation (NAO) index (Hurrell 1995). The high correlation between the NAO index and the

*E-mail: bauer@pik-potsdam.de
$H_{\mathrm{s}}$ data for winter months in particular suggests that the NAO index might be a useful parameter to predict future changes in wave height from large-scale climate change simulations. Specifically, an increase in $H_{\mathrm{s}}$ can be induced by stronger mean westerly winds in the mid-latitudes as a consequence of larger NAO indices. This coupling mechanism has been demonstrated to be effective from dynamical wave modeling studies (Kushnir et al. 1997, WASA Group 1998).

However, clear evidence for an upward trend in the measured mean wind speeds to explain the trend in the mean wave height is missing (Bacon \& Carter 1993). Furthermore, the correlation of the NAO index with the mean wind data is found to be smaller than with the $H_{\mathrm{s}}$ data. This may have several reasons. Firstly, historical time series of wind data show inhomogeneities due to changing practices in producing the data (Cardone et al. 1990), while wave height data are considered to be more homogeneous. Secondly, wind fields contain relatively large natural variability, 
which diminishes the statistical correlation. Furthermore, the upward trend of the mean wave height might not be induced solely by an increase in mean wind speed but also by a change in wind variability. However, the effect on the mean wave height from changing the wind variability is rather small, as inferred from changing the storm frequency in the North Atlantic (Bauer et al. 2000) or from increasing the high-frequency gustiness (Bauer \& Weisse 2000). The experiment on changed storm frequency revealed that a faster (slower) moving weather stream produced a lower (higher) mean $H_{\mathrm{s}}$ through shortening (lengthening) of the storm duration.

The wind variability on the synoptic scale is most relevant for the evolution of high sea states. In previous investigations the data base was insufficient to analyze the observed growth of the mean wave height with respect to wind variability on the synoptic scale. In particular, resolving a trend on decadal time scales in the frequency, duration, size and intensity of storms, is a difficult exercise. However, climate simulations with increased $\mathrm{CO}_{2}$ scenarios provide indications that the attributes of the North Atlantic cyclones in the storm track may change in future (e.g., Schubert et al. 1998).

In the following, the wind and wave variability on the synoptic scale is analyzed for the North Atlantic, during the $13 \mathrm{yr}$ period from 1981 to 1993. The investigation is based on the $6 \mathrm{~h}$ wind analyses from the atmosphere model of the European Centre for Medium Range Weather Forecast (ECMWF), the wind-driven wave data from the WAM wave model and the measured data from the Ocean Weather Station Mike (OWS M). The dominant modes of variability are determined by wavelet analysis and their interannual changes are compared with NAO changes.

The structure of the study is as follows. In Section 2, the wind and wave height data obtained from dynamical modeling are described. Section 3 shows the correlations of the modeled wind and wave height data with the NAO index. In Section 4, the dominant modes of variability on the synoptic scale are derived from the analysis of wavelet spectra. Emphasis is put on interpretation of the 1987 data, with low NAO index, and of the 1989 data, with high NAO index. The results are discussed in Section 5.

\section{DESCRIPTION OF MODEL DATA}

The atmospheric wind fields are provided by the ECMWF Re-Analysis (ERA) Project (Gibson et al. 1996). The significant wave height fields are obtained with the WAM spectral wave model (Komen et al. 1994), driven by the $6 \mathrm{~h}$ ERA wind fields. The latitude-longitude resolution of wave model is $1^{\circ} \times 1^{\circ}$. The model area comprises the entire Atlantic Ocean and the North Sea. The wave spectrum is resolved by 25 frequencies spaced logarithmically between $0.042 \mathrm{~Hz}$ and $0.41 \mathrm{~Hz}$, and by 24 directions in steps of $15^{\circ}$. Significant wave height and wave period are integral characteristics determined from the ocean wave spectrum. The zonal and meridional components of significant wave height are derived from the mean wave propagation direction of the directionally resolved spectrum. The reanalysis of the wave data is performed for the 13 yr period from 1981 to 1993, with 6-hourly output.

\section{CORRELATION OF WIND AND WAVE DATA WITH NAO INDEX}

The mean large-scale distributions of the winds and of the wind-driven waves resemble the distribution of the horizontal gradients of sea level pressure, according to the geostrophic relationship. Consequently, the

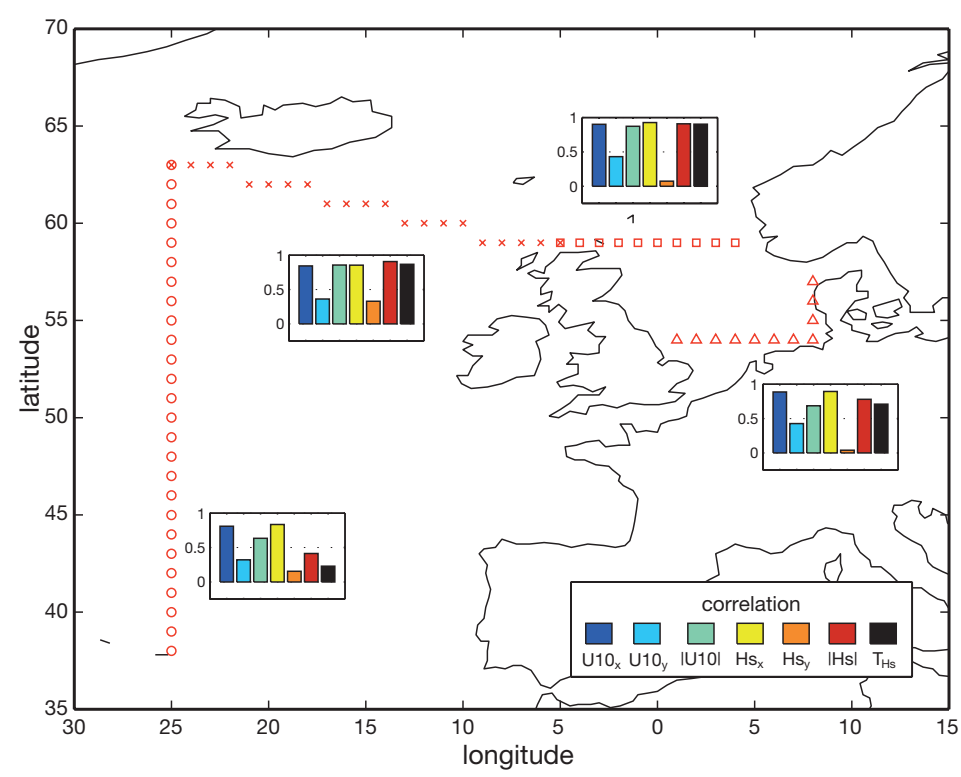

Fig. 1. Distribution of correlation coefficient between winter (December to March) NAO index and wind and wave data, averaged along 3 sections in the NE Atlantic and 1 section in the North Sea, marked by symbols. Correlation coefficients are given for: zonal wind $U 10_{\mathrm{x}}$ (blue), meridional wind $U 10_{y}$ (light blue), wind speed $|U 10|$ (green), zonal significant wave height $H_{\mathrm{S}_{\mathrm{X}}}$ (yellow), meridional significant wave height $H_{\mathrm{S}_{\mathrm{y}}}$ (orange), significant wave height $\mid \mathrm{H}_{\mathrm{S}} \mathrm{l}$ (red), and wave period $T_{H_{\mathrm{s}}}$ (black). Winter NAO index from sea level pressure measurements at Ponta Delgada, Azores and Stykkisholmur/Reykjavik, Iceland; wind data from ECMWF model; wave data from WAM model hindcast for 1981-1993 
zonal components of the wind and the significant wave height along the section between the Azores and Iceland are highly correlated with the NAO index, whereas the meridional wind and wave height components are poorly correlated with the NAO index (Fig. 1). The NAO index is inferred from the meridional difference between sea level pressure measurements at Ponta Delgada, Azores and at Stykkisholmur/ Reykjavik, Iceland. During the winter months the wind and wave data in the northeastern part of the North Atlantic, in the Scotland/Norway region, are more highly correlated with the NAO index than the wind and wave data from the central North Atlantic (Fig. 1). This suggests that the wind fields with zonal motions from west to east extend far eastward of the Azores High and the Iceland Low. The zonality of the west wind band involves a large fetch and a long duration of wind forcing and thus causes eastward enhanced correlations of the NAO index with wave height and period.

The winter NAO index is seen to be considerably more correlated with the wind and wave height data than the monthly mean data (Fig. 2). The time series of the monthly NAO index show fluctuations on semiannual and shorter periods whereas the wind speeds
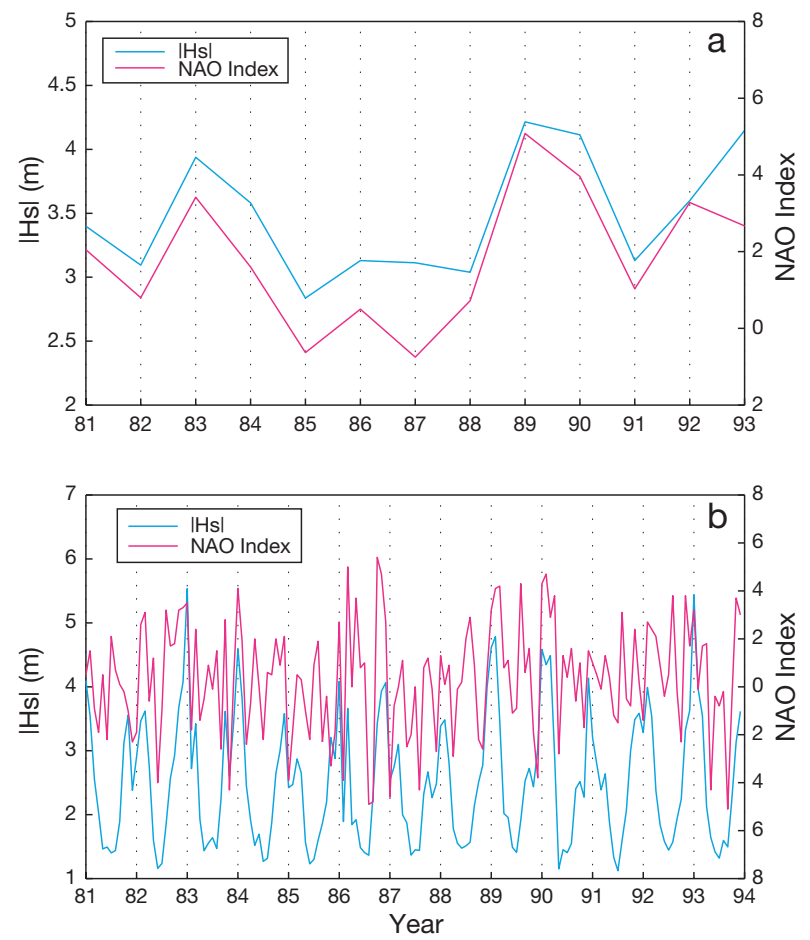

Fig. 2. WAM significant wave heights and NAO index time series from 1981 to 1993. (a) Winter data (December-March), (b) monthly data. Model data averaged along the section between Scotland and Norway (see Fig. 1). The correlation coefficient for the winter data is high (0.91) and for the monthly data is low $(0.47)$ as well as the wave heights vary mainly with the seasonal cycle. The reduced zonality of the westerlies in the monthly data implies more frequent meridionally directed winds in the eastern North Atlantic and the North Sea. This is inferred from the significantly increased correlation between the monthly NAO index and the meridional wind and wave components in the eastern North Atlantic compared to the winter data. For the meridional wave heights the correlation increases up to 0.6 for the monthly data, compared to a correlation of 0.1 for the winter data (Fig. 1).

In the North Sea, however, the correlation coefficient of the NAO index with $H_{\mathrm{s}}$ and the wave period is reduced through the sheltering effect of the British Isles. The largest correlations with the NAO index are obtained for the zonal wind and the zonal wave height component during winter (Fig. 1). This again indicates a wide extension of the zonal motions over the Northeast Atlantic and the North Sea during winter.

\section{WAVELET ANALYSIS}

High-resolution time series of the wind and wave data show, besides the seasonal variability, large contributions from nonsteady and turbulent motions on the smaller scales. The dominant modes of the synoptic-scale variability are estimated using wavelet spectrum analysis. Wavelet analysis is a useful method to estimate dominant scales of variability as a function of time, from time series containing transient or temporally localized events. The wavelet spectrum analysis yields a power distribution as a function of time and scale. This method was applied to ocean wind waves for the first time by Liu (1994), who studied wave growth with winds from measured buoy time series of $1 \mathrm{~s}$ resolution. In this study modeled and measured time series of wind and significant wave height with $6 \mathrm{~h}$ resolution are analyzed. For practical reasons, the $13 \mathrm{yr}$ time series from 1981 to 1993 is divided into $1 \mathrm{yr}$ sections. From each section the seasonal cycle was filtered out by subtracting the monthly means. Thus, in the anomaly time series, it is mainly the variability on the synoptic scale that is retained.

The wavelet power spectra are computed with the so-called 'Mexican hat' wavelet which is equivalent to the second derivative of the Gaussian (DOG). DOG wavelets are continuous, non-orthogonal and realvalued wavelet functions which are preferable for signal analysis (Farge 1992). In comparison to other continuous wavelet functions, such as the Morlet or the Paul wavelet, the Mexican hat wavelet yielded smoother wavelet power spectra.

Results are presented from the model time series at a location close to the station of OWS M. Fig. 3b displays 
the wavelet power spectrum of the modeled significant wave height at $\left(66^{\circ} \mathrm{N}, 2^{\circ} \mathrm{E}\right)$ from the anomaly time series of 1987 (Fig. 3a). The wavelet power spectrum $E$ is defined, in analogy to the Fourier power spectrum, as the square of the absolute value of the wavelet transform $W$ of the anomaly time series:

$$
E(t, s)=|W(t, s)|^{2}
$$

where $t$ denotes the time and $s$ the scale. The wavelet transform $W$ here is determined from the inverse Fourier transform of the complex conjugate product between the Fourier-transformed 'Mexican hat' wavelet and the Fourier-transformed time series.

From the wavelet power spectrum $E(t, s)$ follows the global wavelet spectrum $E_{\mathrm{g}}$ from averaging over time (here 1 yr):

$$
E_{g}(s)=\frac{1}{N} \sum_{i=0}^{N-1} E\left(t_{i}, s\right)
$$
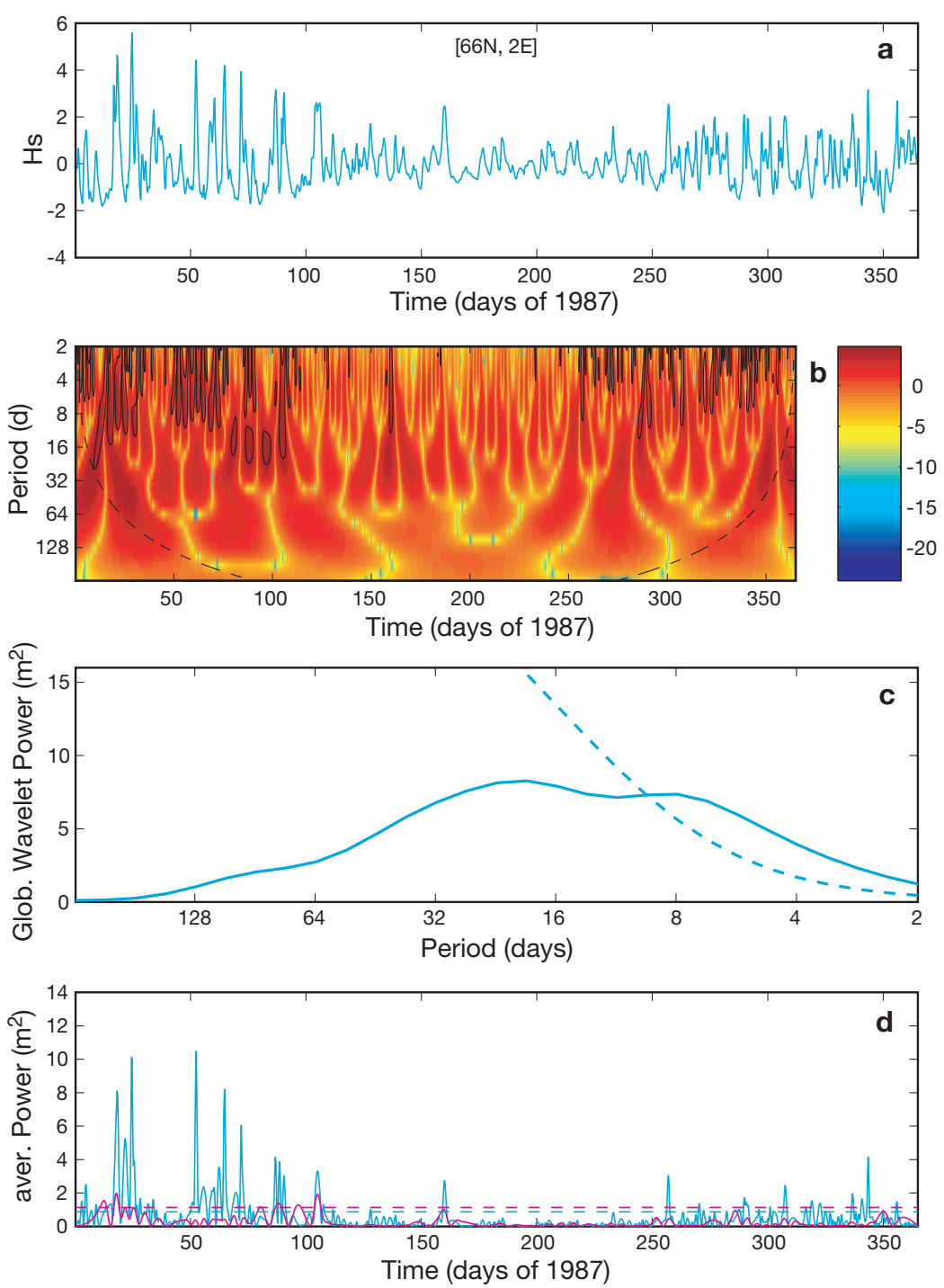

In this way the global wavelet spectrum (Fig. 3c) becomes comparable to the Fourier power spectrum. For direct comparison, the scale $s$ is converted to the corresponding Fourier period in Fig. 3.

An alternative way of smoothing the wavelet power spectrum is by averaging over a band of scales $s_{j 1}$ to $s_{j 2}$ :

$$
E_{\mathrm{b}}(t)=\frac{1}{C_{\mathrm{b}}} \sum_{j=j_{1}}^{j_{2}} \frac{E\left(t, s_{j}\right)}{s_{j}}
$$

where $C_{\mathrm{b}}$ is a normalization factor and $s_{j}$ denotes a discrete scale. The scale-averaged wavelet power $E_{b}$, which can be expressed by the corresponding periodaveraged wavelet power, is useful to demonstrate the different temporal variation of wavelet power for different bands of periods. The period-averaged wavelet power may be significant in a localized time interval, even if the global wavelet power is not significant in that band of periods. This is evident from comparing

Fig. 3d and 3c. Further details on wavelet spectrum analysis can be found in Torrence \& Compo (1998).

The wavelet spectra of the wind speed and wave height data from modeling and measurements of the same year are seen to resemble each other very closely. Their dominant modes of variability, expressed by the Fourier period, lie in the range of 8 to $54 \mathrm{~d}$. Some of the wavelet spectra also show a secondary mode, and in 1985 even a third mode is visible (not shown). The occurrence of secondary modes within $1 \mathrm{yr}$ indicates that the winds and the waves are composed of varying localized contributions, which complicates the description of the attributes of synoptic-scale wind variability.

Fig. 3. (a) Anomaly time series of $H_{\mathrm{s}}$ from WAM model with $6 \mathrm{~h}$ resolution $\left(66^{\circ} \mathrm{N}, 2^{\circ} \mathrm{E}\right)$ for 1987 , when NAO index was low. Anomaly time series is without seasonal cycle and normalized with standard deviation. (b) Contour plot of wavelet power spectrum using DOG wavelet as function of Fourier period in days and time in days. Color shading displays $\log$ (wavelet power) in units of variance $\left(\mathrm{m}^{2}\right)$. Black contour lines indicate significantly enhanced wavelet power at $95 \%$ confidence with respect to fitted red noise. Dashed line (cone of influence) marks the periods beyond which the wavelet power is affected by edge effects. (c) Global wavelet spectrum, depending on period from time-average of wavelet power spectrum in (b). Dashed line marks mean background spectrum inferred from red noise. (d) Period-averaged wavelet power (blue) in 2-9.5 d band and (red) in 9.5-38 d band as function of time. Dashed lines: $95 \%$ confidence levels 
In comparison to the wavelet spectrum analysis for the 1987 data (Fig. 3) the wavelet spectrum for 1989 data from the same location is shown in Fig. 4. The data for 1987 and 1989 are chosen from the 13 yr period because the annual mean values of significant wave height in the Northeast Atlantic are found to be very low in 1987 and high in 1989. At the same time, the NAO indices were low in 1987 and high in 1989. The comparison of wavelet spectra shows that the peak wavelet power and the peak period in the modeled wind and wave height data also increase with growing NAO index. This is more clearly evident from the wavelet analysis of measured wind speeds and $H_{\mathrm{s}}$ at OWS M (Table 1). However, the shift in the peak values of the wavelet spectra should be considered only qualitatively, because the estimates of wavelet power are significant only at the shorter periods. At the longer periods, peak values are below the $95 \%$ confidence level, derived from the background red noise spectrum as shown in Figs 3c \& 4c.

In the North Sea, the wavelet spectra of wind speeds and wave heights are also very similar, but the shift of the dominant parameters of the North Sea wavelet spectra from 1987 to 1989 is reversed compared to the Northeast Atlantic data (Table 1). In the North Sea, the peak value of the wavelet power spectrum and the peak period are larger in 1987 (Fig. 5) than in 1989 (Fig. 6). This indicates that in times of high (low) NAO index, when the large-scale atmospheric circulation has stronger (weaker) zonal components and weaker (stronger) meridional components, the synoptic-scale variability in the North Sea experiences less (more) influence from the North Atlantic storm track.

\section{CONCLUSIONS}

The large-scale distribution of winddriven ocean waves in the North Atlantic is related on the one hand to the largescale distribution of the gradient of sea level pressure, according to the geostrophic relationship, and on the other hand to the integral process of wave generation. This explains the high correlation
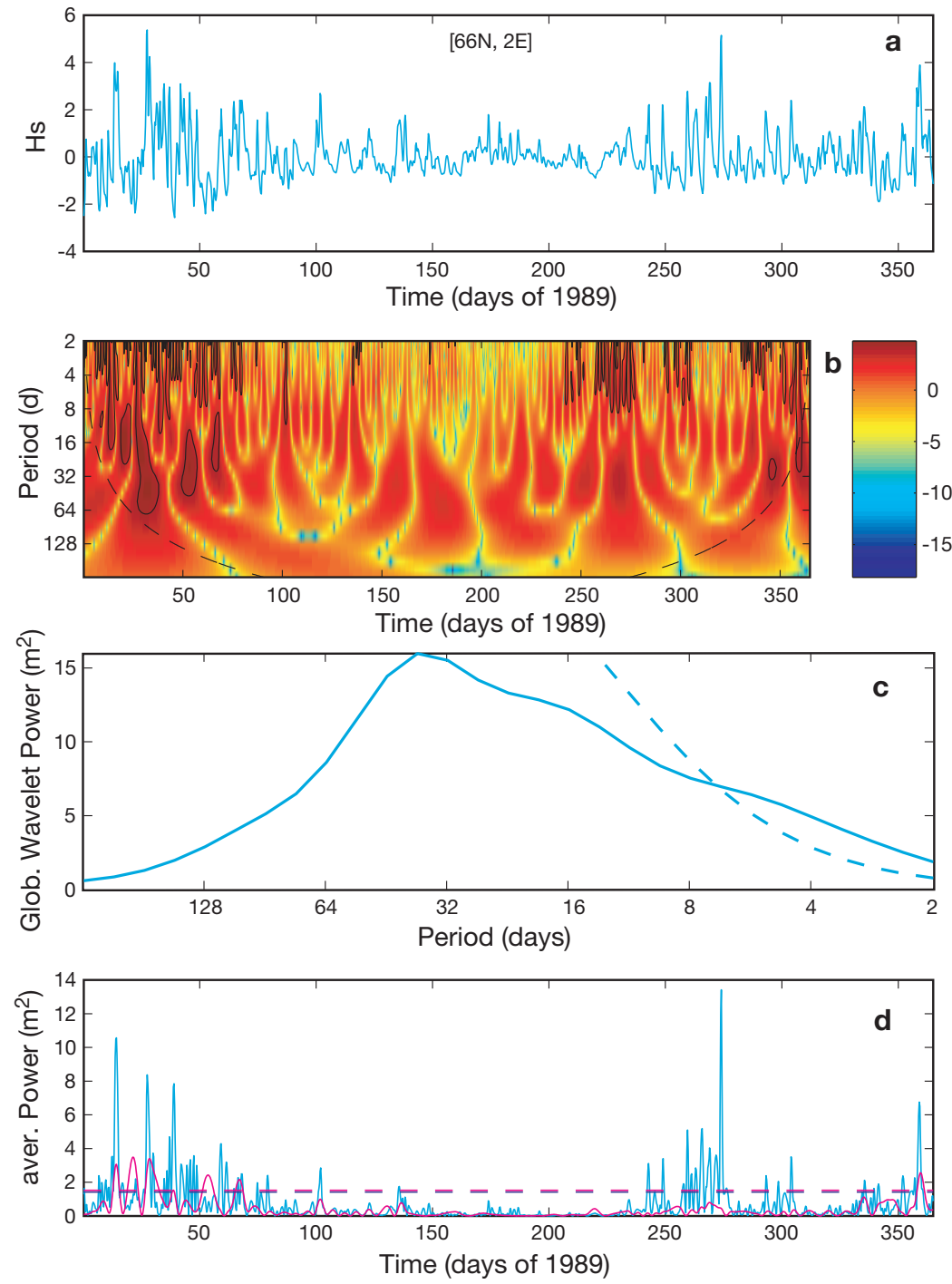

Fig. 4. Same as Fig. 3 but for 1989 time series of $H_{\mathrm{s}}$, when NAO index was high

Table 1. Peak values of global wavelet power $E_{p}$ and peak period $p_{p}(\mathrm{~d})$ obtained from $6 \mathrm{~h}$ time series for 1987 and 1989, with low and high NAO index respectively. Time series of wind speed $u$ and significant wave height $H_{\mathrm{s}}$ taken from measurements of OWS M in Northeast Atlantic, from ECMWF model and WAM model at the same location $\left(66^{\circ} \mathrm{N}, 2^{\circ} \mathrm{E}\right)$, and from the ECMWF model and the WAM model in southern North Sea $\left(54^{\circ} \mathrm{N}, 7^{\circ} \mathrm{E}\right)$

\begin{tabular}{|llccccc|}
\hline Location & \multirow{2}{*}{ Time series } & \multicolumn{2}{c}{1987} & \multicolumn{2}{c}{1989} \\
& & & $E_{p}$ & $p_{p}$ & $E_{p}$ & $p_{p}$ \\
\hline NE Atlantic & OWS M $u$ & $78.4 \mathrm{~m}^{2} \mathrm{~s}^{-2}$ & $7.9 \mathrm{~d}$ & $100.4 \mathrm{~m}^{2} \mathrm{~s}^{-2}$ & $53.5 \mathrm{~d}$ \\
& ECMWF & $u$ & $79.4 \mathrm{~m}^{2} \mathrm{~s}^{-2}$ & $31.8 \mathrm{~d}^{\mathrm{a}}$ & $76.2 \mathrm{~m}^{2} \mathrm{~s}^{-2}$ & $45.0 \mathrm{~d}$ \\
& OWS M & $H_{\mathrm{s}}$ & $7.3 \mathrm{~m}^{2}$ & $7.9 \mathrm{~d}$ & $15.5 \mathrm{~m}^{2}$ & $53.5 \mathrm{~d}$ \\
& WAM & $H_{\mathrm{s}}$ & $8.3 \mathrm{~m}^{2}$ & $18.9 \mathrm{~d}$ & $16.0 \mathrm{~m}^{2}$ & $37.8 \mathrm{~d}$ \\
North Sea & ECMWF $u$ & $108.4 \mathrm{~m}^{2} \mathrm{~s}^{-2}$ & $37.8 \mathrm{~d}$ & $56.8 \mathrm{~m}^{2} \mathrm{~s}^{-2}$ & $15.9 \mathrm{~d}$ \\
& WAM & $H_{\mathrm{s}}$ & $11.1 \mathrm{~m}^{2}$ & $37.8 \mathrm{~d}$ & $7.5 \mathrm{~m}^{2}$ & $15.9 \mathrm{~d}$ \\
a Global wavelet spectrum has significant secondary peak at $8 \mathrm{~d}$ & \\
\hline
\end{tabular}



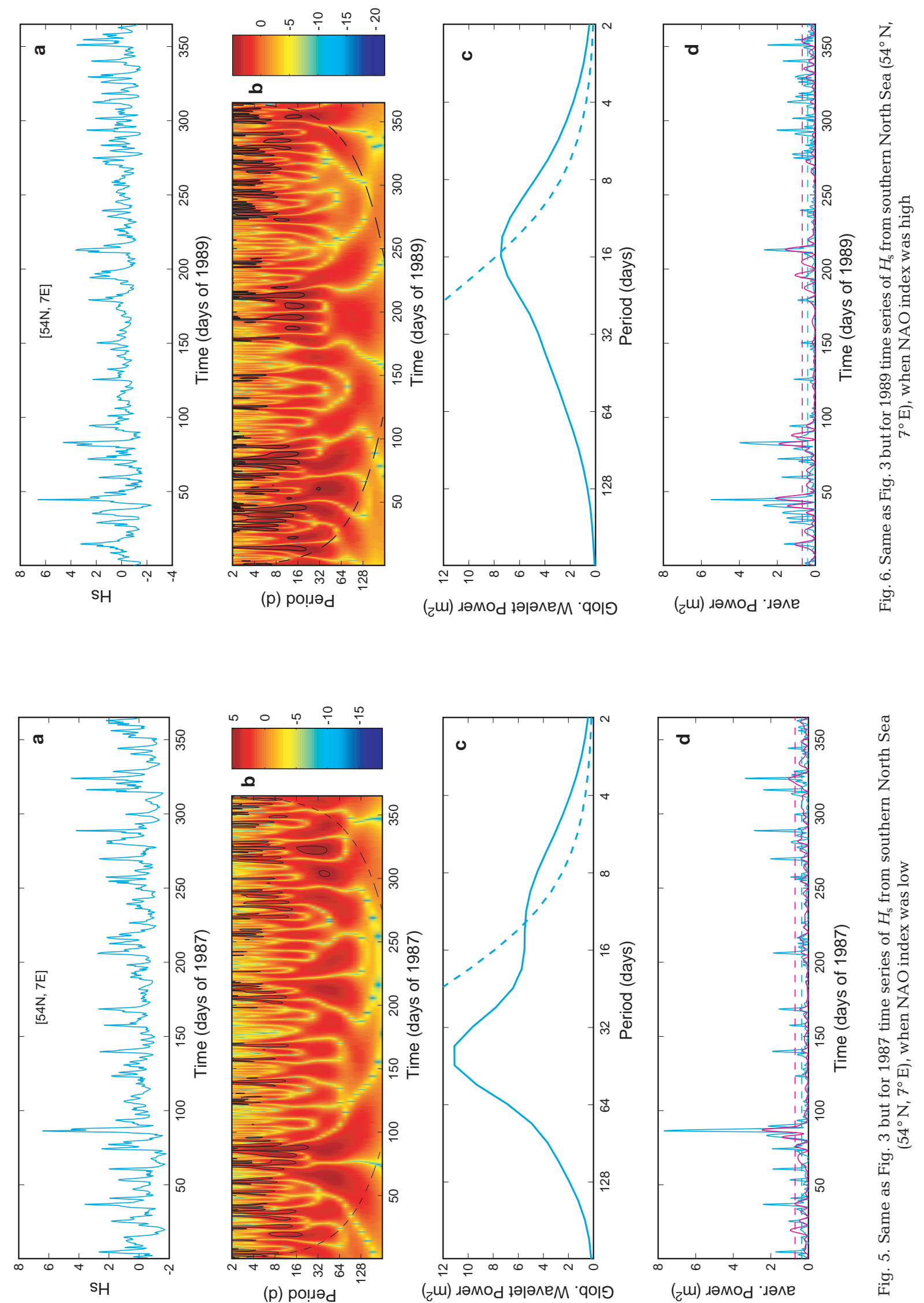

(p) poiləd

(¿ш) цәмод ғәәәем 'qоㅟ

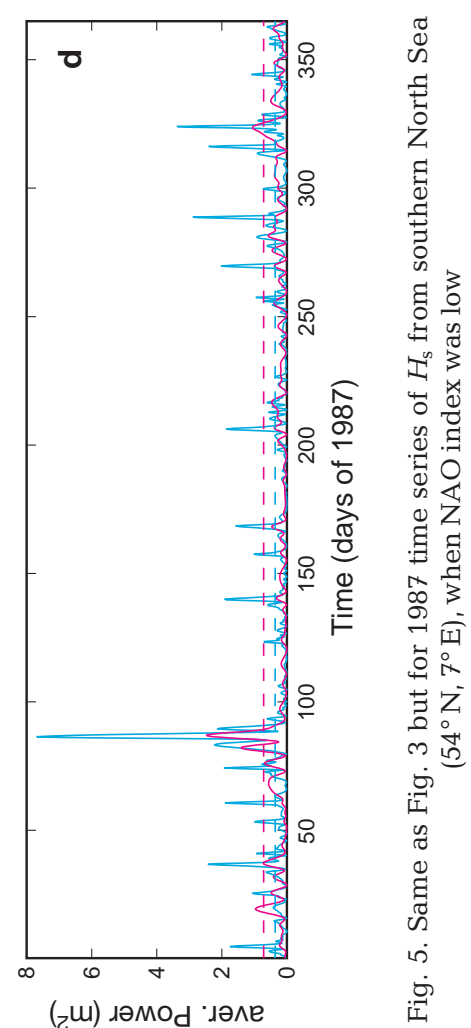


between significant wave height in the North Atlantic and the NAO index, in particular during winter. In the eastern North Atlantic the cumulative wave growth, connected with longer wind duration and fetch, results in a larger correlation of the NAO index with the wave data (wave height and period) than with wind speed. In addition to large-scale characteristics, the $6 \mathrm{~h}$ time series of wind and wave height data reveal considerable contributions of different strength from synopticscale variability, which are localized mainly in winter.

An attempt to describe the dominant periods of the synoptic-scale variability is made using reanalyzed as well as measured data of wind speed and significant wave height from 1981 to 1993. The wavelet power spectra determined for $1 \mathrm{yr}$ sections representing anomalies from the seasonal cycle show relatively large interannual changes. The dominant period of variability derived from the 13 time series varies between 8 and $54 \mathrm{~d}$. The increase of the NAO index from 1987 to 1989 appears to be accompanied by a significant growth of the annual mean significant wave height, the dominant wavelet power and the dominant period of the wavelet power. This indicates that the high sea states in the Northeast Atlantic in 1989 may result partly from the increased strength of the westerlies and partly from an intensification of the synopticscale variability. But from the present analysis no general conclusion can be drawn on a systematic relationship between the zonality of the westerly winds and storminess in mid-latitudes. To obtain a better statistical description, longer time series are required.

The close resemblance between the wavelet power spectra obtained from the modeled wind and wave height data and those from measured time series at OWS M provides confidence in the usefulness of the atmosphere and wave model simulations. As wave heights in the Northeast Atlantic are closely correlated with the winter NAO index, the winter NAO index appears to be a useful predictor. This implies that predictions of the future development of the winter NAO index may be used to estimate future changes in wave height for the North Atlantic. But the interaction between large-scale changes and synoptic-scale variability is seen to be highly nonlinear. In addition, regional differences play a role as interannual changes on the synoptical scale in the North Atlantic are seen to be quite different to those in the North Sea. Neverthe- less, dynamical models of the atmosphere and of ocean waves appear to be valuable tools to infer information on large-scale and synoptic-scale variability, which is needed for taking precautions in the routing of ships and for the inhabitants of the zone.

Acknowledgements. This study was funded by the Bundesminister für Bildung und Forschung, Bonn, under project KLINO (Climatology of spectral wave data in the North Sea and the Baltic Sea, 03F0185A).

\section{LITERATURE CITED}

Bacon S, Carter DJT (1991) Wave climate changes in the North Atlantic and North Sea. Int J Climatol 11:545-558

Bacon S, Carter DJT (1993) A connection between mean wave height and atmospheric pressure gradient in the North Atlantic. Int J Climatol 13:423-436

Bauer E, Weisse R (2000) Determination of high-frequency wind variability from observations and application to North Atlantic wave modeling. J Geophys Res 105 (C11) 26179-26190

Bauer E, von Storch H, Stolley M (2000) Sensitivity of ocean waves to speed changes of the weather stream. Glob Atmos Ocean Syst 7:91-106

Bouws E, Jannink D, Komen GJ (1996) The increasing wave height in the North Atlantic Ocean. Bull Am Met Soc $77: 2275-2277$

Cardone VJ, Greenwood JG, Cane MC (1990) On trends in historical marine wind data. J Climate 3:113-127

Farge M (1992) Wavelet transforms and their application to turbulence. Annu Rev Fluid Mech 24:395-457

Gibson R, Kallberg P, Uppala S (1996) The ECMWF ReAnalysis (ERA) project. ECMWF Newsletter 73:7-17

Hurrell JW (1995) Decadal trends in the North Atlantic Oscillation: regional temperatures and precipitation. Science 269:676-679

Komen GJ, Cavaleri L, Donelan M, Hasselmann K, Hasselmann S, Janssen PAEM (1994) Dynamics and modelling of ocean waves. Cambridge University Press, Cambridge

Kushnir Y, Cardone VJ, Greenwood JG, Cane MA (1997) The recent increase in North Atlantic wave heights. J Climate 10:2107-2113

Liu PC (1994) Wavelet spectrum analysis and ocean wind waves. In: Foufoula-Georgiou E, Kumar P (eds) Wavelets in geophysics. Academic Press, San Diego, p 151-166

Schubert M, Perlwitz J, Blender R, Fraedrich K, Lunkheit F (1998) North Atlantic cyclones in $\mathrm{CO}_{2}$-induced warm climate simulations; frequency, intensity, and tracks. Clim Dyn 14:827-837

Torrence C, Compo GP (1998) A practical guide to wavelet analysis. Bull Am Met Soc 79:61-78

WASA Group (1998) Changing waves and storms in the Northeast Atlantic? Bull Am Met Soc 79:741-760 